\title{
PERFORMANCE EVALUATION IN KOSOVO ORGANIZATIONS
}

\section{Thëllëza Latifi Sadrija ${ }^{1}$}

\begin{abstract}
The performance means the behavior and the resultant measured based on certain activities and duties. Enterprises performance could be measured thanks to indicators that express the quality of its activities. While, for individuals and groups, it is hard to identify the link between their performance and that of the company. Performance evaluation is an instrument through which the employees within the organization can reflect, discuss and change their work method that influences the organizational effectiveness. The focus of this paper is to argue that effective performance, feedback, and employee training are necessary for the success of an organization, and at the same time the development plan to support the employees in achieving the best possible results is necessary too. The employees' training in Kosovo's enterprises is closely related to the organization, and the planning of employees in a way to so they are prepared at a national level and the attempt to exchange employees and train them in international level. This would affect the effective performance and cultures exchanged.
\end{abstract}

JEL Classification Numbers: M1, M11; DOI: http://dx.doi.org/10.12955/cbup.v5.937

UDC Classification: 659

Keywords: performance, enterprise, culture, evaluation, effectiveness.

\section{Introduction}

Taking into consideration the fact that employees are the most important assets in an organization and the organizations' effectivity is based on the work and the capabilities of its employees to realize organizational objectives, motivation, and an employee's evaluation are the most important factors to achieve the aims of the organization. Performance management is a process focused on the employees in a way to contribute to achieving the objectives of the organization. This is necessary for every organization. In fact, performance management includes different types of systems.

The system of performance management is one of the management performance forms. Supervisors and managers are responsible for managing the performance of their employees. Any organizational policy should specify how it will be implemented in the performance management systems. The organizations should adapt their performance management practices, which are in accordance with the requirements of these policies to better fit the nature of the work and mission of the organization.

Of all the activities of human resources management, performance evaluation is the most argumentative, the more voluminous and the least popular method considered by the people who are involved in it. However, despite the impression on the evaluation within the organization is not highly appreciated this must be part of the organization management including some basic rules through which the performance is measured, monitored and controlled.

The aim of the paper: the aim of this paper consists of analyzing methods and practices used in Kosovo organizations to improve their performance, and whether or not the organization applies mechanism like employee training and staff rewards.

Basic hypothesis: to evaluate the performance, motivation methods are used like training and staff rewards.

Research question 1: Are the employees in Kosovo businesses rewarded?

Research question 2: do the organizations use motivating methods like staff rewards and training?

The objective of the study:

The creation of a questionnaire with private businesses in the city of Peja, in a way to show what are the problems that these organizations are facing with HRM. Analysing the qualitative and statistical information. Presenting the conclusions based on the results of the questionnaire that is created, that deals with training and rewards of employees.

\section{Literature review}

Human resources are considered to be the most valued asset of the organization. But, only a few organizations use their full human potential in their organizations. The system and human resource

\footnotetext{
${ }^{1}$ University Haxhi Zeka Peja/Kosovo, thelleza.latifi@unhz.eu
} 
practices are defined as a set of activities, functions, and processes that are connected to each other and directed to attract, develop and retain the human resources and the group. An important issue of human resources management is the idea that an appropriate combination of human resources policies and the implementation of the same are necessary to achieve a high performance (Wright \& Boswell, 2002).

Performance management is a process that contributes to the effective management of individuals and teams in ways to achieve a high level of organizational performance. As such, it sets equal understanding of what needs to be achieved and an approach in guiding and developing people that will ensure its achievement (Armstrong \& Baron, 2004).

Performance management is a systematic approach to improve individual performance and team performance in order to achieve organizational goals.....the approach one should take depends on their organization, its culture, relationship with employees and the types of jobs they do (Hendry et al., 1997).

Performance evaluation - making employees know exactly what is required from them in order to improve their performance or change their behavior and it also helps them to stay focused

Periodic feedback helps employees to self-correct continuously and give them a feeling of control in the results of their performance. The ability to make changes and improve their performance leads to employee motivation and helps them to renew their efforts. Human resource managers who use the objective and scientific performance measures are most able to motivate their employees better.

The employees' evaluation consists of different forms of evaluation: when employees are evaluated based on the work they do and are trained for additional advancements, where they are rewarded in monetary form when they are motivated by acknowledgments and rotational position, through which the organization determines the value and express their qualities.

The evaluation of the employees is a process that happens continuously within organizations consciously or not. When we appreciate something, we try to determine the value, usefulness, and the qualities (Koli \& Llaci, 2001)

Businesses have the advantage to decide the culture and organizational environment for their employees. If we talk about models that explain the connection between managers and employees for Kosovo organizations we are based on the critical-evaluation model of personnel manager (Legge, 1987).

Human resources managers very often behave according to a profitability view and the efficiency of the organization. Based on this view/model the businesses should not focus on the welfare of employees. Human resources managers do not deal with the individual development of employees. All activities of training and development are realized with the aim to improve the affectivity of employees with the aim to contribute more to the organization.

\section{Methodology used:}

The present paper is divided into two parts: the theoretical part and the empirical part. In the theoretical it part includes all the aspects that are related to human resources and performance evaluation as important factors that influence business effectiveness. The theoretical interpretation of this part explains the relation and the treatment of employees in an organization as a most valuable asset.

The empirical part includes the research that is realized through the questionnaire, the hypothesis is tested, and the interpretation of results is done. For the realization of the research, we are based in primary data. The questionnaire is distributed in private businesses, respectively their employees in the city of Peja in different departments. 280 questionnaires are distributed, and only 200 of them are valid for further analysis.

Registration of businesses by ownership structure: 


\begin{tabular}{|l|l|r|}
\hline \multicolumn{2}{|l|}{ Table 1: Ownership structure of enterprises } & Percentage \\
\hline Ownership structure & Number of businesses & $92.83 \%$ \\
\hline Individual Business & 6613 & $2.75 \%$ \\
\hline General Partnership & 196 & $0.07 \%$ \\
\hline Limited Partnership & 5 & $4.08 \%$ \\
\hline Limited Liability Company & 291 & $0.11 \%$ \\
\hline Joint Stock Company & 8 & $0.14 \%$ \\
\hline $\begin{array}{l}\text { Enterprises in Foreign } \\
\text { Ownership }\end{array}$ & 10 & $0.0 \%$ \\
\hline Social Enterprices & 0 & $0.01 \%$ \\
\hline Public Enterprises & 1 & $0.01 \%$ \\
\hline Agricultural Cooperative & 1 & $\mathbf{1 0 0 \%}$ \\
\hline TOTAL & $\mathbf{7 1 2 5}$ & \\
\hline
\end{tabular}

Source: Municipal center for business registration in Peja/Kosovo (MCBR)

\begin{tabular}{|c|c|c|}
\hline Type of activity & Number of businesses & Percentage \\
\hline Trade & 3050 & $42.80 \%$ \\
\hline Services & 1884 & $26.40 \%$ \\
\hline Production & 984 & $13.90 \%$ \\
\hline Construction & 317 & $4.40 \%$ \\
\hline Hotels and restaurants & 890 & $12.50 \%$ \\
\hline TOTAL & 7125 & $100 \%$ \\
\hline
\end{tabular}

Source: Municipal center for business registration in Peja/Kosovo (MCBR)

The research is focused on service and production businesses in the city of Peja. The results will be drawn from the responses of managers of those companies surveyed and based on these results every question is interpreted while also the labor market and employees' requests are analyzed.

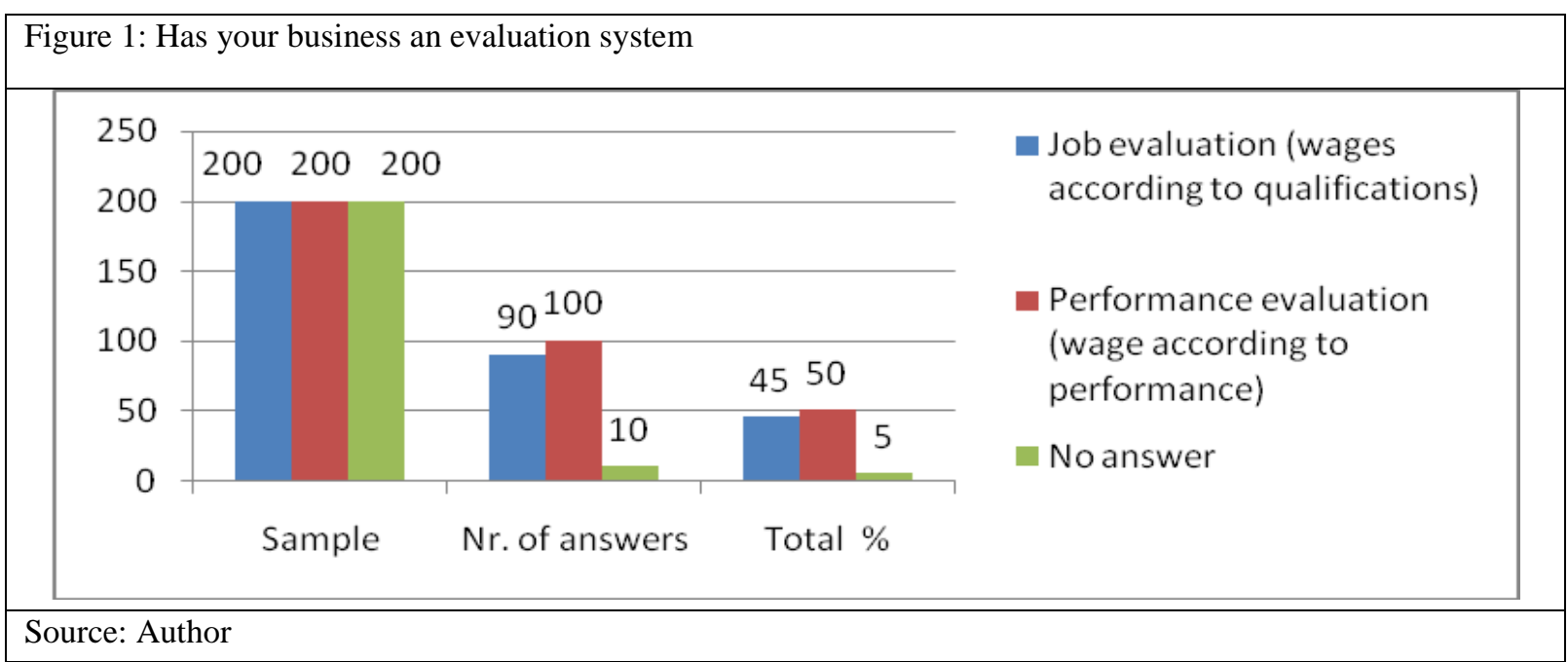

To the question: "Has your business an evaluation system?" Based on Figure 1 about $75 \%$ of managers have a positive answer result with effectiveness as an important information and necessary for the function, the possibility to express to the employer what they expect to achieve and as well as a general understanding of organizational culture. 


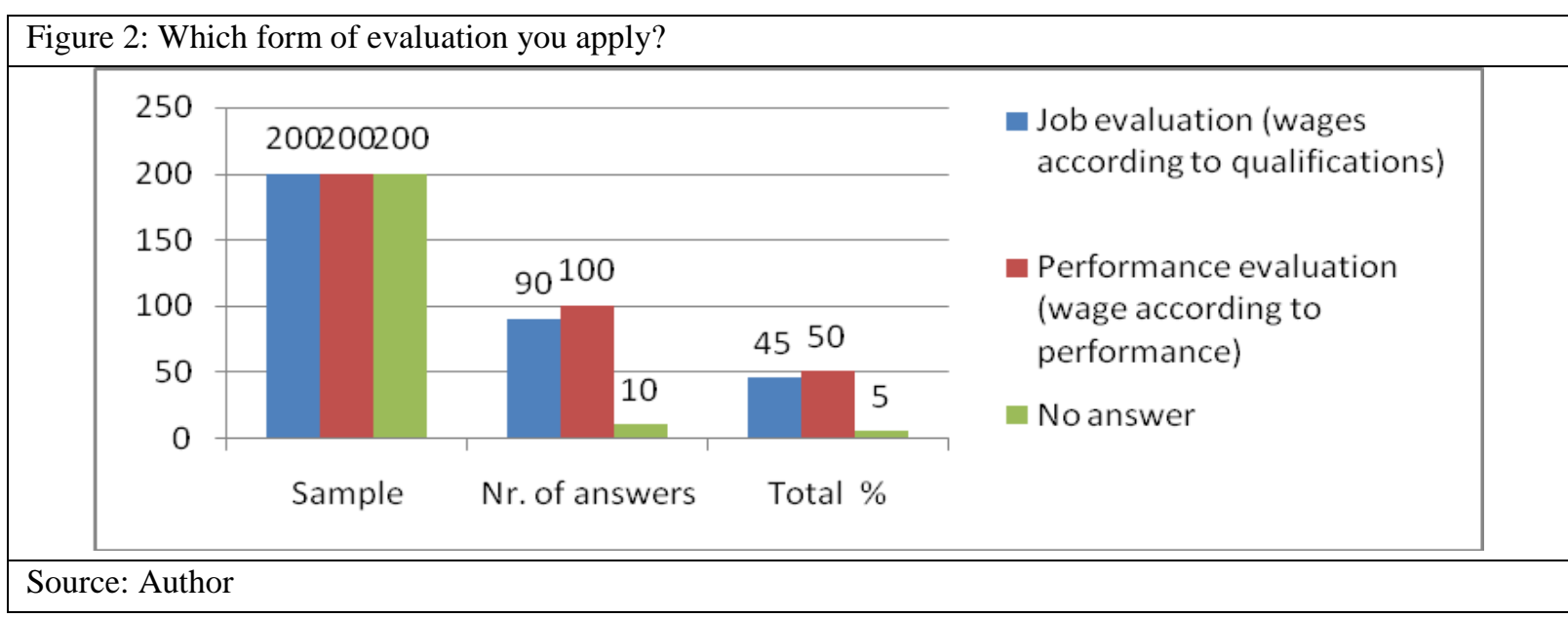

To the question: "which form of evaluation you apply", from a total of 200 managers 100 of them answered that the businesses apply the method "wage based on performance" of evaluation performance, where the effectiveness is that they pay the employees based on merit, incentive wages that increase motivation, rewards, share splits.

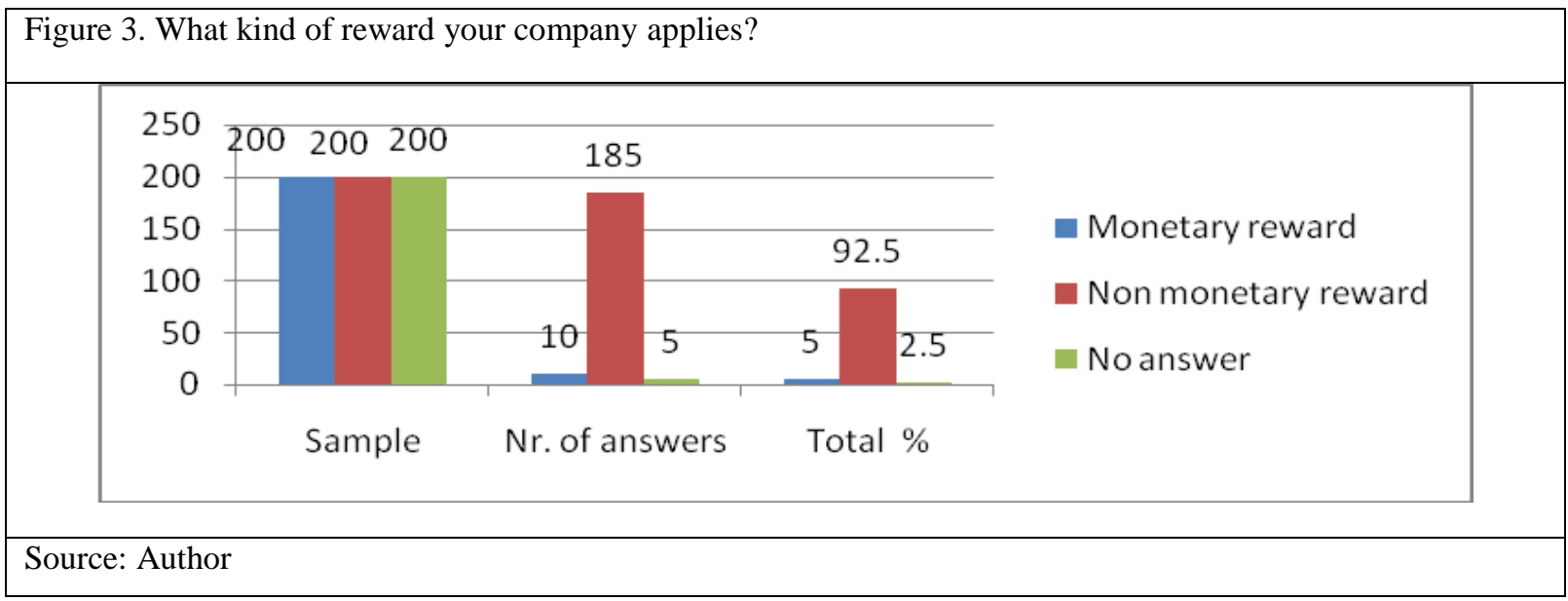

To the question: "what kind of reward your company applies," $92.5 \%$ of the answers of managers are a non-monetary reward. In fact, these kinds of rewards influence employee performances, either through intangible benefits of values such as career, social services such as job security, flexible work hours, professional growth, acknowledgments and strong friendship.

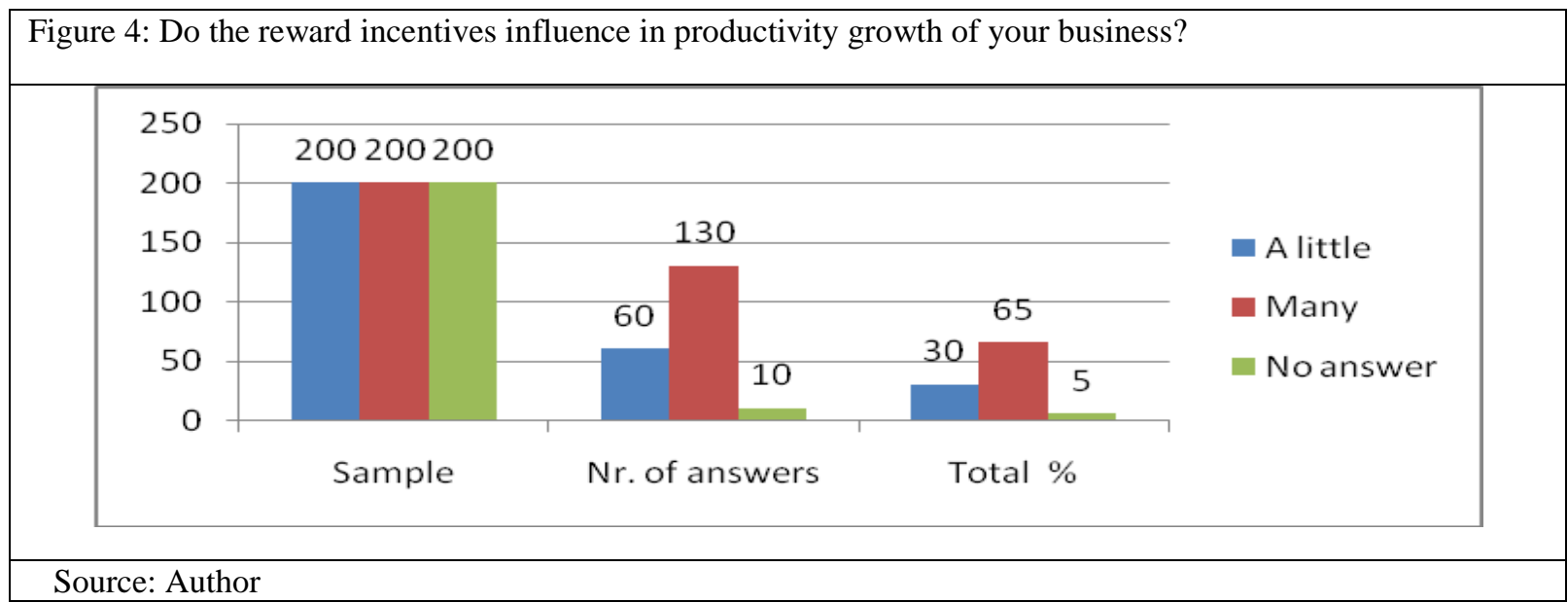

To the fourth question, $65 \%$ of managers declare that reward incentives influence the productivity growth, $30 \%$ of them declare that it influences less, and 5\% of them abstained to this question. 


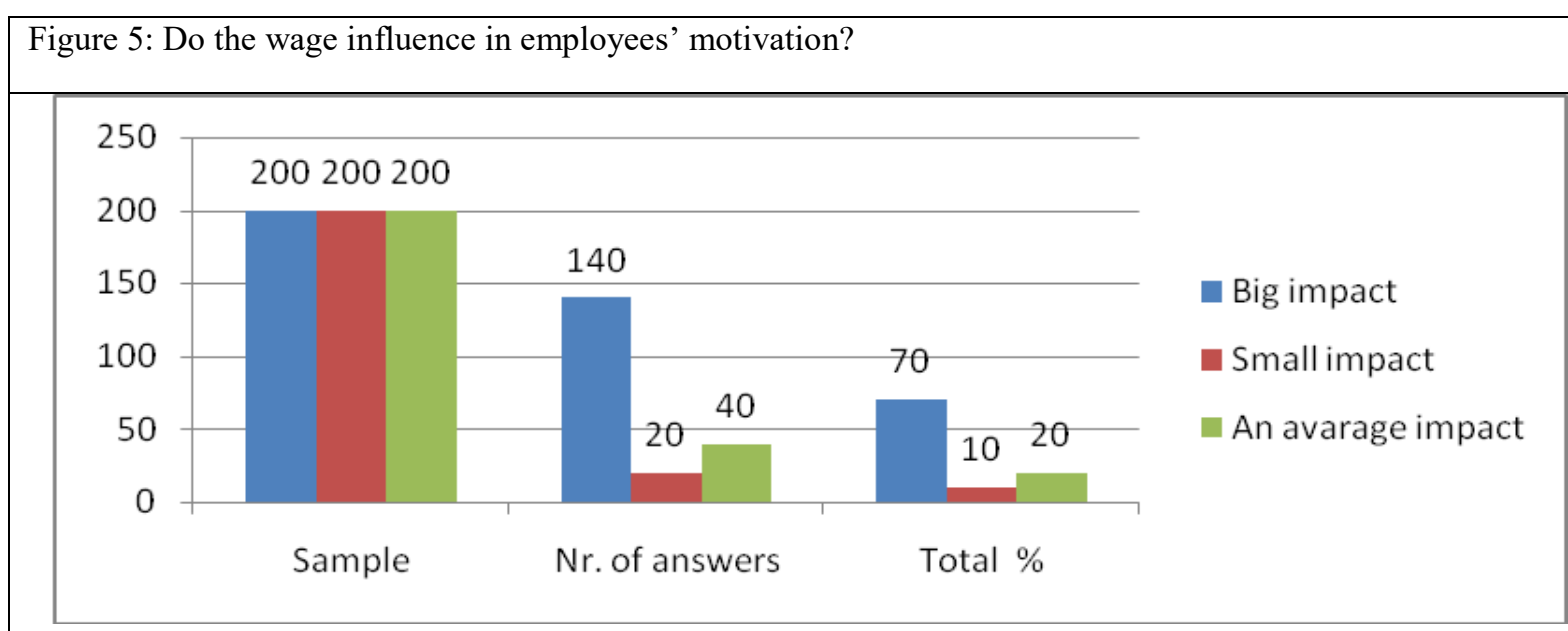

Source: Author

To the fifth question, $65 \%$ of managers declare that reward incentives influence the productivity growth, $30 \%$ of them declare that it influence less, and $5 \%$ of them abstained to this question.

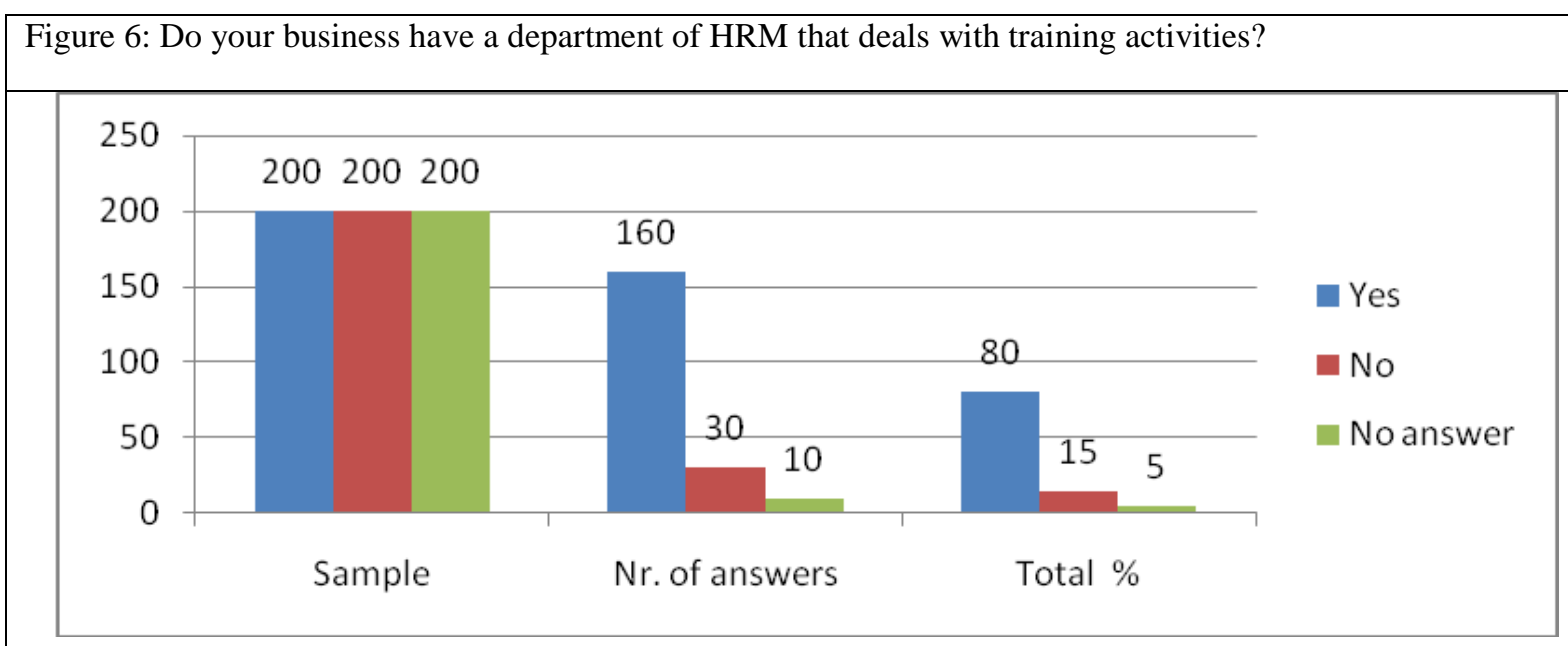

Source: Author

According to the statistics presented for the above question, $80 \%$ of managers declare that the department of HRM for training activities exists in their businesses and represent an important development factor.

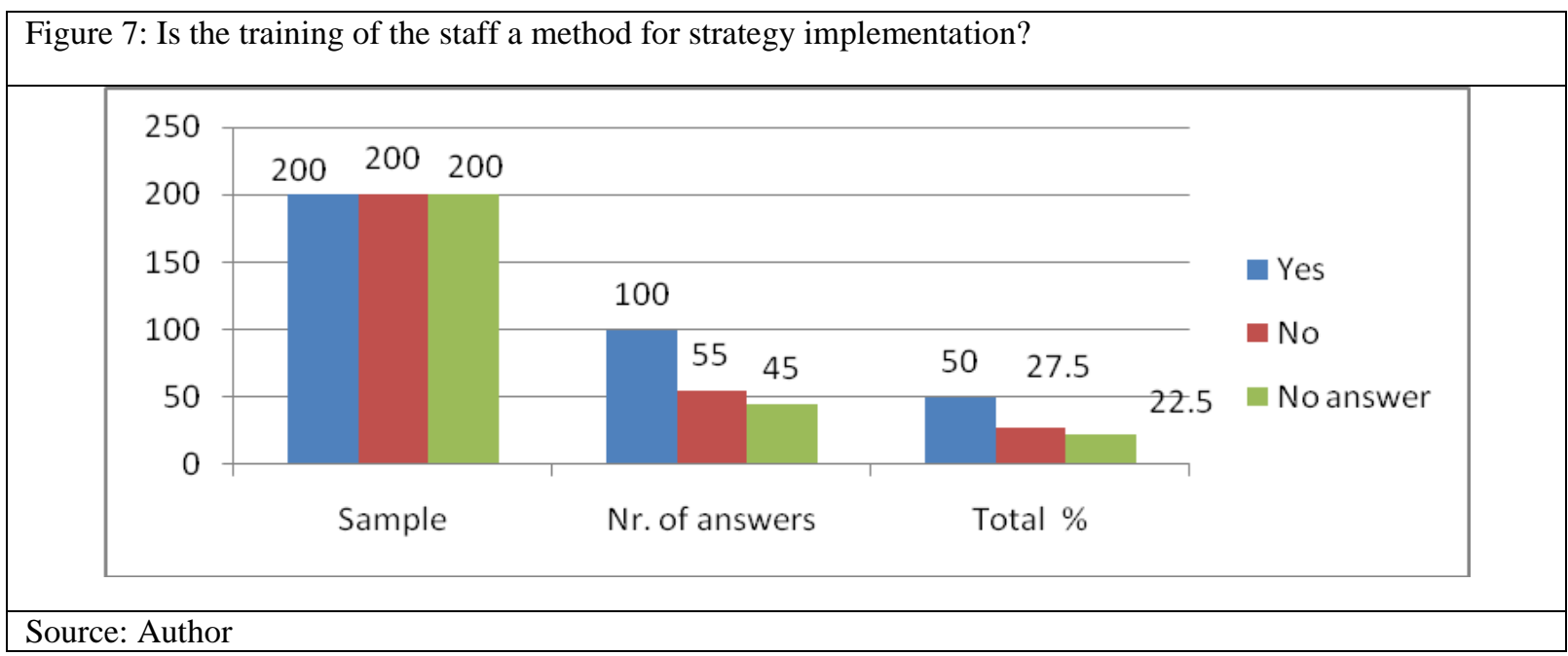


To this question, $50 \%$ of managers have answered positively, and the other part does not support the training of the staff as a part of the strategy.

Figure 8: Are retrained employees evaluated and do they participate in the decision-making process?

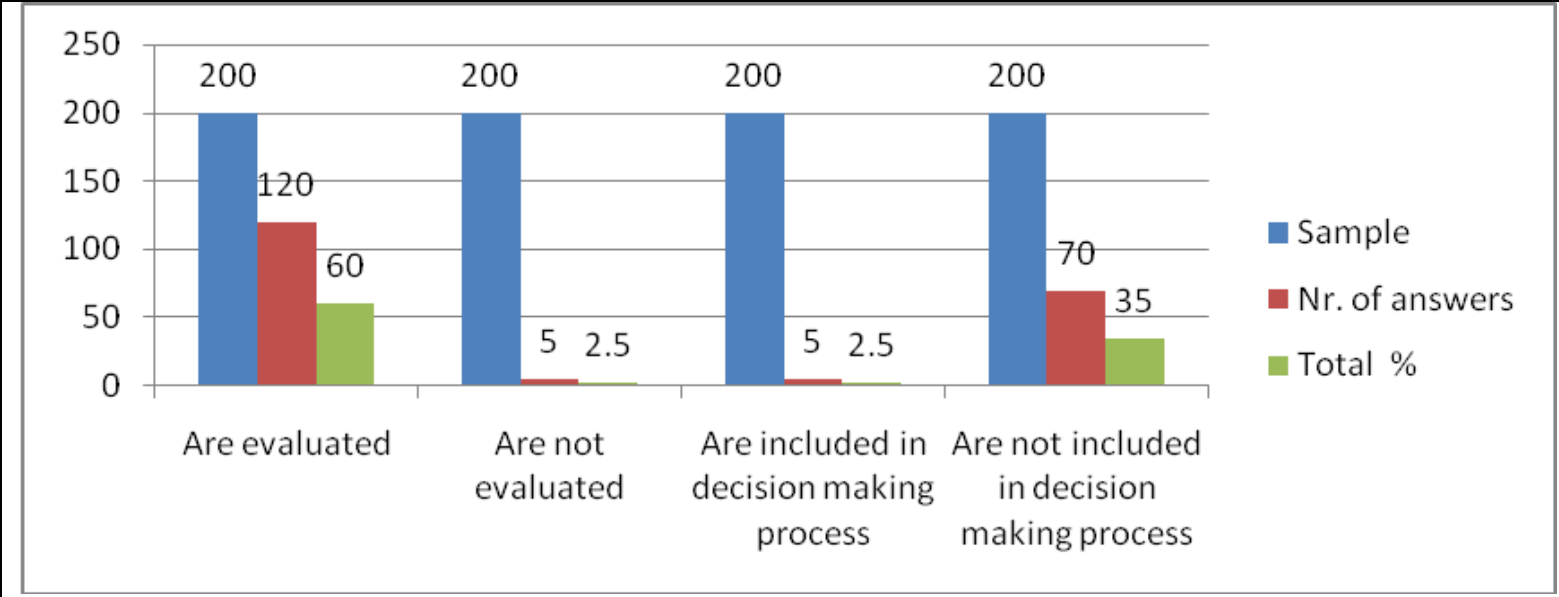

Source: Author

To this question if the trained staff is evaluated and if they participate in the decision-making process the results are that they are evaluated but are not included in the decision-making process.

Figure 9: If you train your employees do you think that these employees will leave the organization?

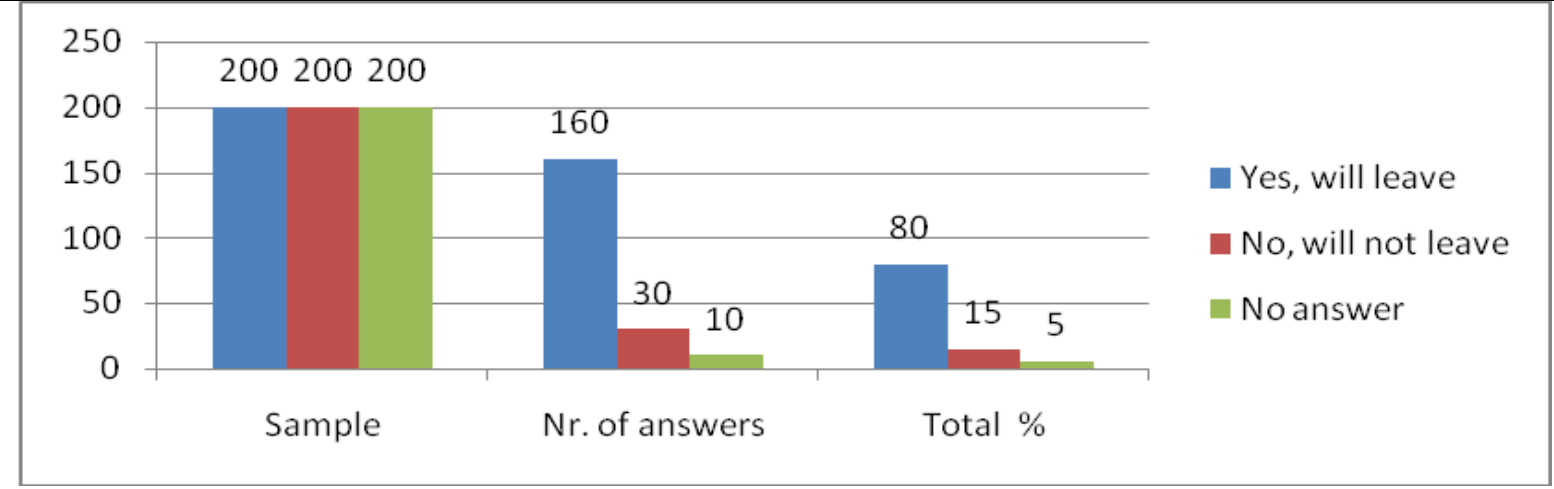

Source: Author

To this question if the trained employees will leave the organization $80 \%$ of managers declare positively.

\section{Conclusion:}

The success of the organization is related to employee training. Here are included the job satisfaction and employee motivation that try to give the best of them for the consumers, and in this way, they achieve success for their owners or shareholders. Through this two objectives are achieved: the objective of the organization and the objective of the employees.

We can certainly say that in Kosovo the application of the modern concept of the motivation of human resources, as is done in Western countries, is the far way in our organizations.

The political and economic instability (wage differences in Kosovo is much lower with respect to other European countries) that exists in Kosovo has created a disadvantage that directly affects the fact that motivation is a very important factor for increasing the performance, the application of a more reward system in the form of cash a reward since our country is facing the problem of low salaries. Another conclusion, based on the statistics is that employees are evaluated, but they do not take part in the decision-making process. This must be changed, and the employees must have the right to give 
their ideas in a way to have more innovations within organizations. Develop a training culture where all the specialized and not specialized employees can participate

We can conclude that the rewards based on performance motivate and guarantees the success of the company

\section{References}

Armstrong, M. and Baron, A. (2004) Managing Performance: Performance management in action. London: CIPD. Pilbeam, S., \&Corbridge, $M$.

Aswathappa, K. (2002). Human Resource \& Personal Management (3rd edition)TMH, 39-50

Gully,. S., Cshen G (2010) "Individual Differences" Attribute-Treatmant Interactions and Trainnig Outcomes”. Learning Training and development in organizations, edituarnga Kozlowski, A., Salas, E.p 3-64

Hendry et al. 1997. The effects of farm environment and management on laminitis.

Keith, N., Frese,M., (2008), "Effectiveness of Error Management Training: A Meta-Analysis", Journal off applied psychology, 93(1), pp. 59-69

Micheal Amstrong., (2000). PerformanceManagament "key startegies and practical guidelines"

Monks, K. 1993. 'Models of personnel management: a means of understanding the diversity of personnel practices?', Human Resource Management Journal, 3(2), 29-41

Sahinidis, A.G. and J. Bouris, (2008).“Employee perceived training effectiveness relationship to employee attitudes” Journal of European Industrial Training. Volume: 32 Issue: 1 Pp. $63-76$

Ulrich, D. (1997) Human resource champions: the next agenda for adding value and delivering results. Boston, MA: Harvard Business School Press.

Wright, dhe Boswell, 2002. Desegregating HRM (2): A Review and Synthesis of Micro and Macro Human Resource Management Research

Zana Koli., Shyqyri Llaci., 2001. Menaxhimi I Burimeve Njerëzore . 